\title{
Fractionation of DMSO-Extracted and NaOH-Extracted Hemicelluloses by Gradient Ethanol Precipitation from Neosinocalamus affinis
}

\author{
Genque Fu, ${ }^{1}$ Panpan Yue, ${ }^{1}$ Yajie Hu, ${ }^{1}$ Nan Li, ${ }^{1}$ Zhengjun Shi $\left(\mathbb{D},{ }^{2}\right.$ and Feng Peng $\left({ }^{1}\right.$ \\ ${ }^{1}$ Beijing Key Laboratory of Lignocellulosic Chemistry, Beijing Forestry University, Beijing 100083, China \\ ${ }^{2}$ College of Material Science and Technology, Southwest Forestry University, Kunming 650224, China \\ Correspondence should be addressed to Feng Peng; fengpeng@bjfu.edu.cn
}

Received 7 October 2017; Revised 10 March 2018; Accepted 1 April 2018; Published 8 May 2018

Academic Editor: Arthur J. Ragauskas

Copyright ( $\odot 2018$ Genque Fu et al. This is an open access article distributed under the Creative Commons Attribution License, which permits unrestricted use, distribution, and reproduction in any medium, provided the original work is properly cited.

Neosinocalamus affinis hemicelluloses were extracted with pure DMSO and 3\% $\mathrm{NaOH}$ in sequence. The DMSO- and NaOHextracted hemicelluloses were then successively fractionated by gradient ethanol precipitation. $\mathrm{NaOH}$-extracted hemicellulosic fractions with different branch degree could be separated by gradient ethanol precipitation, while DMSO-extracted hemicellulosic fractions could not. FT-IR spectra showed that DMSO-extracted fractions have more complete structure, while $\mathrm{NaOH}$-extracted fractions have no acetyl at all. The FT-IR and NMR revealed that the DMSO-extracted Neosinocalamus affinis hemicelluloses were 4 -O-methyl-glucuronoarabinoxylans consisting of a linear $(1 \rightarrow 4)-\beta$-D-xylopyranosyl backbone with branches at $O-2,3$ of acetyl, $O-2$ of 4-O-methyl- $a$-D glucuronic acid, and $O-3$ of arabinose.

\section{Introduction}

The sharp shrink in the range of available petroleum resource and the gradually severe environmental pollution have led the research of biomass to a hot topic. The utilization of diverse lignocellulosic biomass is indeed worth exploring for sustainable development. Bamboo is a kind of potential lignocellulosic feedstock with desirable advantages such as high productivity and fast growing, which includes 1250 species within 75 genera [1]. There is a wide distribution of it in China, and it is convenient to utilize the biomass resource in papermaking, fabricating bamboo products, textiles, activated carbon, and food industry as well as bioenergy applications [1-4]. Neosinocalamus affinis is one-timing flowering perennial plants that belong to Bambusoideae, a subfamily of Gramineae, which takes a big proportion in economic bamboo species in our country [5]. Up to now, the novel utilization and development of research on Neosinocalamus affinis are still on the way.

Hemicelluloses, the second abundant lignocellulosic resource in nature, are prevailing in botanical materials. This kind of relatively low molecular weight polysaccharides associates with cellulose and lignin through hydrogen bonds and various covalent bonds in plant cell walls. Different botanical origins lead to differences in composition and structures of various hemicelluloses [6]. Hemicelluloses account for $22-35 \%$ of the bamboo composition, and the dominant species is xylan [1]. Due to its excellent property, a great growing trend in utilization of hemicelluloses in chemicals, medicine, and biomaterials has been generated in recent decades $[7,8]$. Chemical and biological methods are the predominant extraction processes for bamboo hemicelluloses. Today, plenty of chemical methods have been well investigated, for example, alkaline extraction, alkaline peroxide extraction, organic solvent extraction, and the biological method mainly which includes enzyme for hydrolysis of bamboo cell walls $[9,10]$. In addition, treatments such as ultrasonic irradiation, steam explosion, ultrafiltration, and autohydrolysis treatment are used for effective fractionation of hemicelluloses [11-14]. Alkaline extraction is one of the most effective methods employed for the isolation of hemicelluloses, but this method has the disadvantage of deacetylating 


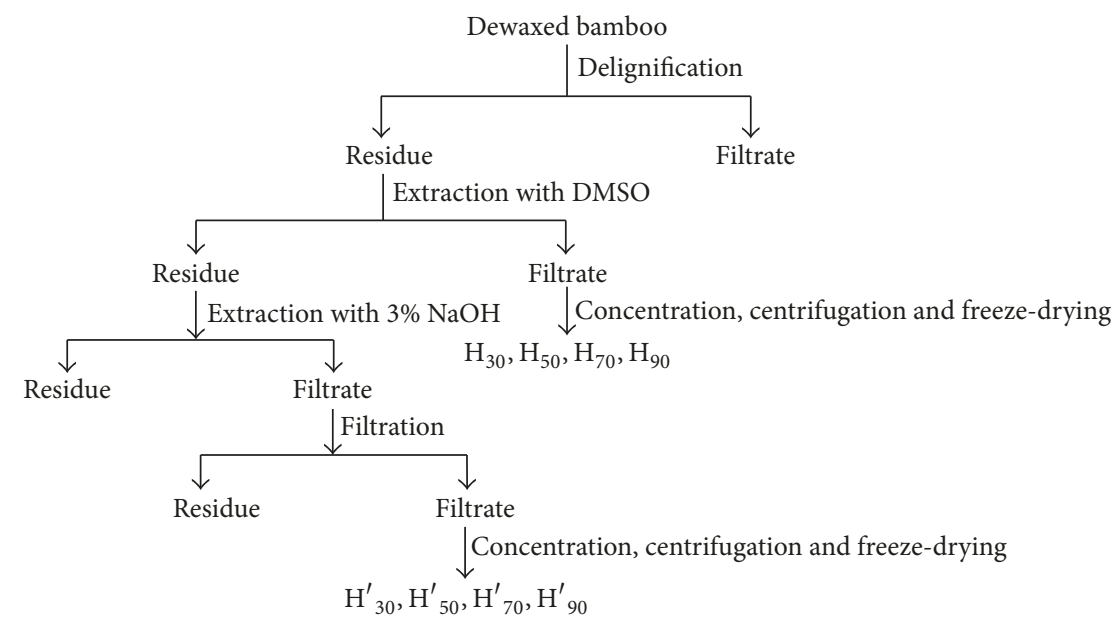

FIGURE 1: Scheme for extraction and fractionation of hemicelluloses from Neosinocalamus affinis.

hemicelluloses [15]. Compared with alkali, DMSO is an ideal solvent for extraction of polysaccharides from plant, which can well remain both $O$-acetyl group and glycosidic linkages of hemicelluloses [16]. Hemicelluloses with various structures are also extracted by $\mathrm{DMSO} / \mathrm{LiCl}$ system successfully from some plant materials $[17,18]$. The isolated hemicelluloses generally consist of various populations of polysaccharide molecules which vary in structural characteristics, and several fractionation techniques such as sodium sulfite precipitation and gradient ethanol precipitation have been employed in order to obtain more homogeneous fractions [15].

In our group, the gradient ethanol precipitation technique has been used for fractionating alkali-extracted hemicelluloses. It was found that, with an increment of ethanol concentration, the arabinose/xylose (Ara/Xyl) and glucuronic acid/xylose (GlcA/Xyl) ratios of the alkali-extracted hemicellulosic fractions increased. The two ratios reflect the branch degree of xylan from gramineous plants. Namely, the less branched alkali-extracted hemicelluloses are likely to be precipitated by ethanol with low concentration, while the highly substituted alkali-extracted hemicelluloses are preferred to be fractionated by ethanol with high concentration [19]. The purpose of the current work is to investigate the condition that DMSO-extracted hemicelluloses are precipitated by ethanol with gradient concentration, and a comparison will be made with the result of $\mathrm{NaOH}$-extracted hemicelluloses. Furthermore, high performance anion exchange chromatography (HPAEC), Fourier-transform infrared (FT-IR) spectroscopy, and nuclear magnetic resonance spectroscopy (NMR) are employed to obtain structure characteristic of the hemicellulosic fractions.

\section{Experimental}

2.1. Materials. Neosinocalamus affinis was harvested in Sichuan province, China. They were dried in sunlight, cut into small pieces $(1-3 \mathrm{~cm})$, and then ground to pass through a $0.8 \mathrm{~mm}$ screen. The chemical components of the bamboo culms were determined according to the standard of National
Renewable Energy Laboratory (NREL) [20], and the results were expressed on a percentage basis of the oven-dry raw material. The chemical composition of the dewaxed bamboo was as follows: $50.8 \%$ glucose, $22.9 \%$ xylose, $1.1 \%$ arabinose, $19.5 \%$ galactose, $17.0 \%$ Klason lignin, $2.5 \%$ acid-soluble lignin, and $2.5 \%$ ash. To remove the non-cell wall components, such as wax and chlorophyll, the powder was extracted with toluene/ethanol $(2: 1, \mathrm{v} / \mathrm{v})$ in a Soxhlet apparatus for $6 \mathrm{~h}$ and then overdried at $60^{\circ} \mathrm{C}$ for $16 \mathrm{~h}$. All chemicals used were of analytical or reagent grade.

\subsection{Methods}

2.2.1. Extraction and Fractionation. The process of extraction and fractionation of hemicelluloses from Neosinocalamus affinis is illustrated in Figure 1. The dewaxed bamboo powder was delignified with $6 \%$ sodium chlorite at $\mathrm{pH} 3.6-3.8$, adjusted with aqueous chlorine hydride, at $78^{\circ} \mathrm{C}$ for $2 \mathrm{~h}$. The residue obtained after delignification is holocellulose, which needs to be subsequently washed with distilled water and dried at $60^{\circ} \mathrm{C}$ overnight. Next, the holocellulose powder was extracted by DMSO at $80^{\circ} \mathrm{C}$ for $7 \mathrm{~h}$, using a solid to liquid ratio of $1: 25(\mathrm{~g} / \mathrm{ml})$. After the extraction, the residue was separated from the filtrate with a nylon cloth, washed with distilled water, and further dried in a cabinet oven under air circulation at $60^{\circ} \mathrm{C}$, waiting for following alkali extraction. Next, the filtrate needed to be concentrated at reduced pressure to around $20 \mathrm{ml}$. Ethanol was carefully added to the concentrated filtrate up to $30 \%$ saturation. After a night, the precipitation was centrifuged ( $3400 \mathrm{rpm}, 10 \mathrm{~min})$, freezedried, and finally labelled as $\mathrm{H}_{30}$. Then the supernatant was subsequently adjusted stepwise to 50, 70, and $90 \%(\mathrm{v} / \mathrm{v})$. The corresponding precipitated hemicelluloses fractions were labelled as $\mathrm{H}_{50}, \mathrm{H}_{70}$, and $\mathrm{H}_{90}$, respectively. Total dried residue was weighted and extracted by $3 \% \mathrm{NaOH}(\mathrm{w} / \mathrm{v})$ at $60^{\circ} \mathrm{C}$ for $6 \mathrm{~h}$, using a solid to liquid ratio of $1: 25(\mathrm{~g} / \mathrm{ml})$. After the extraction, the residue was separated, washed, and dried. Then, the obtained filtrate would go through a dialysis process for a week. Following treatment is as described 
in DMSO-extraction above, including concentration, precipitation by ethanol with certain concentration, and freeze drying. The final four alkali-extracted samples were named as $\mathrm{H}_{30}^{\prime}, \mathrm{H}_{50}^{\prime}, \mathrm{H}_{70}^{\prime}$, and $\mathrm{H}_{90}^{\prime}$, respectively.

2.2.2. Analytical Methods. The constituent neutral sugar in the isolated hemicellulosic fractions was determined by high performance anion exchange chromatography (HPAEC). The hemicellulosic fraction $(\sim 5 \mathrm{mg})$ in a sealed tube was hydrolyzed by $1 \mathrm{M} \mathrm{H}_{2} \mathrm{SO}_{4}$ at $105^{\circ} \mathrm{C}$ for $2.5 \mathrm{~h}$, and the neutral sugar was obtained. Then, the hydrolyzed sample was diluted 50-fold, filtered, and injected into the HPEAC system (Dionex ISC 3000) with an amperometric detector, an AS 50 autosampler, and a CarbopacTM PA20 column $(4 \times 250 \mathrm{~mm}$, Dionex), and a guard PA-20 column $(3 \times 30 \mathrm{~mm}$, Dionex $)$ [21]. Calibration was performed with standard solutions of L-arabinose, D-glucose, D-xylose, D-mannose, D-galactose, glucuronic acid, and galacturonic acids. FT-IR experiments were conducted using a TensorII Sample Compartment RTDLaTGS. Dried samples were ground and pelletized using $\mathrm{KBr}$, and their spectra were recorded from 4000 to $400 \mathrm{~cm}^{-1}$ at a resolution of $4 \mathrm{~cm}^{-1}$ and 16 scans per sample. The solution-state ${ }^{1} \mathrm{H}$ and ${ }^{13} \mathrm{C}$ NMR spectra were recorded on a Bruker NMR spectrometer at $400 \mathrm{MHz}$. The samples $(15 \mathrm{mg}$ in $0.55 \mathrm{ml}$ of DMSO- $\mathrm{d}_{6}$ for ${ }^{1} \mathrm{H}, 65 \mathrm{mg}$ in $0.55 \mathrm{ml}$ of DMSO- $\mathrm{d}_{6}$ or ${ }^{13} \mathrm{C}$ ) were prepared as required. The degree of acetylation $\left(D_{\mathrm{AC}}\right)$ was determined from the relative intensities of signals of the acetyl group at $2.1 \mathrm{ppm}$ and those of all carbohydrate signals in ${ }^{1} \mathrm{H}$ NMR spectra. The following equation was used:

$$
\begin{aligned}
& \mathrm{DS}_{\mathrm{AC}} \\
& =\frac{(\text { sum of integrals for acetyl groups at } 2.1 \mathrm{ppm}) / 3}{(\text { sum of integrals for carbohydrate signals at } 3.0-5.5 \mathrm{ppm}) / 6} .
\end{aligned}
$$

The proton-detected heteronuclear single quantum correlation (HSQC) spectra were acquired by the HSQCGE experiment mode [19], over a $t_{1}$ spectral width of $10,000 \mathrm{~Hz}$ and a $t_{2}$ width of $1800 \mathrm{~Hz}$, and the acquired time (AQ) was $0.1163 \mathrm{~s}$. The number of scans (NS) was 32. The delay between transients was $2.6 \mathrm{~s}$, and the delay for polarization transfer was set to correspond to an estimated average ${ }^{1} \mathrm{H}-{ }^{13} \mathrm{C}$ coupling constant of $150 \mathrm{~Hz}$. Data processing was performed using standard Bruker Topspin-NMR software.

\section{Result and Discussion}

3.1. Yield and Sugar Composition. A wide variation in content and chemical structures of large amounts of hemicelluloses exists in plant cell walls, and hemicelluloses are generally composed of several populations of polysaccharides molecules which vary in structural characteristics. Hemicelluloses are formed with lignin by covalent bonds and with acetyl units and hydroxycinnamic acids by ester linkages; in addition, extensive hydrogen bonding among the individual polysaccharides in the cell wall is also formed. These complicated structures remain obstacles for liberation of hemicelluloses from cell wall matrix [21]. In the present work, hemicelluloses from Neosinocalamus affinis are extracted with DMSO at $80^{\circ} \mathrm{C}$ for $6 \mathrm{~h}$ and precipitated
TABLE 1: Yields of hemicelluloses during extraction with DMSO and $\mathrm{NaOH}$ based on starting holocellulose.

\begin{tabular}{lc}
\hline Fraction & Yield (\% delignified material) \\
\hline Extracted with DMSO & 9.65 \\
Extracted with $\mathrm{NaOH}$ & 11.03 \\
\hline
\end{tabular}

stepwise in ethanol with different concentrations. After DMSO-extraction, around $9.65 \%$ of the starting holocellulose was recovered (Table 1). Stepwise addition of ethanol to the DMSO-extracted solution resulted in four fractions, named as $\mathrm{H}_{30}, \mathrm{H}_{50}, \mathrm{H}_{70}$, and $\mathrm{H}_{90}$, respectively. Table 1 shows the yields and composition of the four fractions extracted with DMSO and $\mathrm{NaOH}$. Obviously, for DMSO-extraction, the major hemicellulosic fraction $\left(\mathrm{H}_{50}\right)$ was obtained at the ethanol concentration of $50 \%$, which accounted for $6.23 \%$ of the delignified materials. The yield of $\mathrm{H}_{70}(0.82 \%)$ is a little higher than that of $\mathrm{H}_{30}(0.56 \%)$ and $\mathrm{H}_{90}(0.45 \%)$. The total yield of the four fractions is $8.06 \%$, indicating that there are some small amounts of hemicelluloses, mainly degraded oligosaccharides or other low molecule substances, that are not recovered. Counterpart information of $\mathrm{NaOH}$-soluble hemicelluloses was also included in Table 1 . After the $3 \%$ $\mathrm{NaOH}$ extraction, about $11.03 \%$ of the starting holocellulose was obtained (Table 1), and this is a little higher than that of DMSO-extraction. Four fractions were named as $\mathrm{H}_{30}^{\prime}, \mathrm{H}^{\prime}{ }_{50}$, $\mathrm{H}^{\prime}{ }_{70}$, and $\mathrm{H}^{\prime}{ }_{90}$ after gradient ethanol precipitation. The most recovered group is $\mathrm{H}^{\prime}{ }_{50}(1.69 \%)$, and the yield of $\mathrm{H}^{\prime}{ }_{70}(1.64 \%)$ is a little less, while the yield of $\mathrm{H}^{\prime}{ }_{90}(0.04 \%)$ was really less compared with the other three fractions. The sum of the four yields is $4.15 \%$ which is much less than that of DMSOextracted hemicellulose. This can be explained that the alkali extraction led to severe degradation of hemicelluloses; thus parts of oligo- or monosaccharides could not be recovered in this circumstance.

The composition of the hemicellulosic fractions obtained from the DMSO-soluble hemicelluloses of Neosinocalamus affinis is shown in Table 2. Whatever fraction it is, xylose is the predominant composition accounting for $93.6-95.4 \%$ of the total sugar. Arabinose and glucuronic acid are the other two main components, which account for $2.8-4.0 \%$ and $1.1-1.5 \%$, respectively. This result suggests that glucuronoarabinoxylans are the substantial proportion of hemicelluloses in the cell wall of Neosinocalamus affinis, and this is in accordance with those found in other bamboo species [22]. Less galactose $(0.3-0.5 \%)$ and glucose $(0.5-1.0 \%)$ are also present in the fractions. The small portion of galactose may come from arabinogalactan, and the glucose is probably due to $\beta$-Dglucan, which is a group of polysaccharides found in the cell wall of grain, including grasses and cereals, and this needs to be further proved [23, 24]. Arabinoxylan and glucuronoarabinoxylan with various botanic resources own the same basic chemical structure; they differ in the manner of the xylan backbone. The main differences were found in the ratio of arabinose to xylose (Ara/Xyl) and glucuronic acid to xylose (GlcA/Xyl), in the relative proportions and sequence of various linkages between these sugars, and in the presence of other substituents $[25,26]$. The ratios of Ara/Xyl 
TABLE 2: The contents of neutral sugars and uronic acid (relative $\%, w / w)$ of hemicellulosic fractions obtained from DMSO-extracted and $\mathrm{NaOH}$-extracted hemicelluloses.

\begin{tabular}{|c|c|c|c|c|c|c|c|c|c|c|}
\hline \multirow{2}{*}{ Subf raction ${ }^{\mathrm{a}}$} & \multirow{2}{*}{ Yield $^{\mathrm{b}}(\%)$} & \multicolumn{5}{|c|}{ Molar composition $^{\mathrm{c}}(\mathrm{mol} \%)$} & \multirow{2}{*}{ GalA } & \multicolumn{2}{|c|}{ Molar ratio $^{\mathrm{d}}$} & \multirow{2}{*}{ DSAC } \\
\hline & & Ara & Gal & Glu & Xyl & GlcA & & Ara/Xyl & GluA/Xyl & \\
\hline $\mathrm{H}_{30}$ & 5.8 & 3.6 & 0.5 & 0.7 & 93.7 & 1.5 & & 0.038 & 0.016 & 0.13 \\
\hline $\mathrm{H}_{50}$ & 64.5 & 4 & 0.4 & 0.5 & 93.7 & 1.5 & & 0.043 & 0.016 & 0.23 \\
\hline $\mathrm{H}_{70}$ & 8.5 & 2.8 & 0.3 & 0.5 & 95.4 & 1 & & 0.029 & 0.011 & 0.28 \\
\hline $\mathrm{H}_{90}$ & 4.7 & 3.8 & 0.5 & 1 & 93.6 & 1.2 & & 0.04 & 0.013 & 0.25 \\
\hline $\mathrm{H}_{30}^{\prime}$ & 7 & 8.5 & 0.3 & 0.3 & 87.5 & 3.4 & 0.1 & 0.097 & 0.039 & \\
\hline $\mathrm{H}_{50}^{\prime}$ & 15.3 & 10.3 & 0.8 & 0.2 & 93.2 & 5.3 & 0.2 & 0.124 & 0.063 & \\
\hline $\mathrm{H}_{70}^{\prime}$ & 14.9 & 23.1 & 4.6 & 0.4 & 62.8 & 8.7 & 0.4 & 0.367 & 0.139 & \\
\hline $\mathrm{H}_{90}^{\prime}$ & 0.4 & 29.8 & 5.8 & 2.6 & 56.2 & 4.8 & 0.9 & 0.53 & 0.086 & \\
\hline
\end{tabular}

${ }^{\mathrm{a}} \mathrm{H}_{30}, \mathrm{H}_{50}, \mathrm{H}_{70}$, and $\mathrm{H}_{90}$ represent the hemicellulosic fractions obtained from DMSO-extracted hemicelluloses and $\mathrm{H}_{30}^{\prime}, \mathrm{H}^{\prime}{ }_{50}, \mathrm{H}^{\prime}{ }_{70}$, and $\mathrm{H}^{\prime}{ }_{90}$ represent the hemicellulosic fractions obtained from $\mathrm{NaOH}$-extracted hemicelluloses. ${ }^{\mathrm{b}}$ Based on DMSO-extracted and $\mathrm{NaOH}$-extracted hemicelluloses (w/w). ${ }^{\mathrm{c}}$ Expressed in relative molar percentages, Ara, arabinose; Gal, galactose, Glc, glucose, Xyl, xylose, GlcA, glucuronic acid, and GalA, galacturonic acid. ${ }^{\mathrm{d}}$ Represented the ratio of arabinose to xylose and glucuronic acid to xylose. ${ }^{\mathrm{e}}$ The degree of acetyl substitution $\left(\mathrm{DS}_{\mathrm{AC}}\right)$ of the four hemicellulosic fractions which are determined by integration of the signals of acetyl groups at $2.01 \mathrm{ppm}$ and those of all carbohydrate signals.

and GlcA/Xyl reflect the degree of linearity or branching of hemicelluloses [27]. Based on the data in Table 1, little differences exist in composition of sugars among $\mathrm{H}_{30}, \mathrm{H}_{50}$, and $\mathrm{H}_{90}$. With increasing the concentration of ethanol, there is also no apparent variation in Ara/Xyl and GlcA/Xyl, and this means the three fractions almost have the same degree of branching. The composition of $\mathrm{H}_{70}$ shows an obvious different result; it has the highest xylose component (95.4\%) and the contents of arabinose and glucose as well as glucuronic acid are much lower compared with the other three fractions. The two molar ratios, Ara/Xyl (0.029) and GlcA/Xyl (0.011), are also much less than that of the others. This suggests that the DMSO-soluble hemicellulosic fraction $\mathrm{H}_{70}$ has more linear chemical structure.

Under the treatment of $\mathrm{NaOH}$ extraction, the molar composition of sugar units is listed. Xylose is the most predominant portion (56.2-93.2\%). Arabinose (8.5-29.8\%) and glucuronic acid (3.4-8.7\%) are two main components, and this is similar to the result of DMSO-extraction. From Table 2, it is obvious that the molar percentage of arabinose and glucuronic acid increased as the concentration of ethanol increases in the precipitation process. Thus, elevating trend of the two molar ratios (Ara/Xyl and GlcA/Xyl) appeared, which is in accordance with our previous studies [28]. As for the DMSO-extracted hemicelluloses, no striking differences among the values of Ara/Xyl and GlcA/Xyl ratios were found, which was probably due to the fact that the DMSOsoluble hemicellulosic fractions possess acetyl groups in structures and the branch degrees of them are too similar to be distinguished by gradient ethanol precipitation. From the above, when compared with DMSO-soluble hemicellulosic fractions, $\mathrm{NaOH}$-soluble hemicellulosic fractions with different degrees of branch could be well distinguished by gradient ethanol precipitation. Namely, there are significant discrepancy of branch degree among the $\mathrm{NaOH}$-soluble hemicellulosic fractions, and gradient ethanol precipitation seems like a satisfied fractionation method for them. For DMSO-soluble hemicellulosic fractions, which own similar

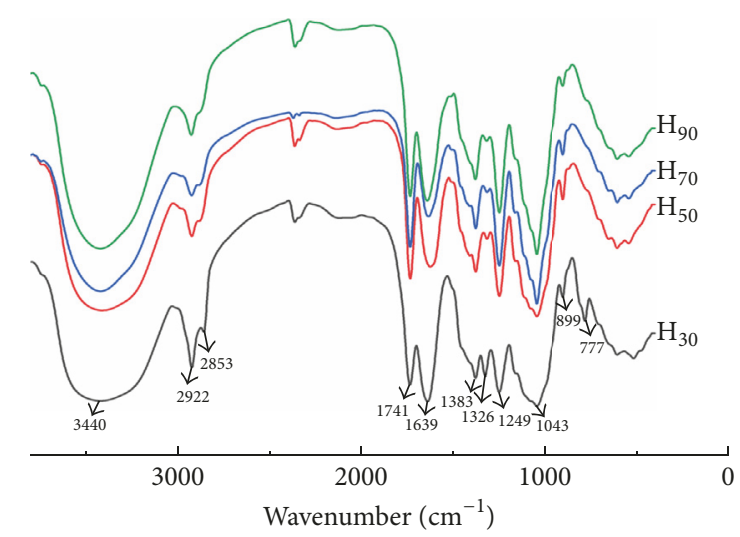

FIGURE 2: FT-IR spectra of DMSO-extracted fractions $\mathrm{H}_{30}, \mathrm{H}_{50}, \mathrm{H}_{70}$, and $\mathrm{H}_{90}$.

branch degrees, gradient ethanol precipitation could not separate them well. A conclusion could be drawn that gradient ethanol precipitation is suitable for fractionation of hemicellulosic fractions with significant discrepancy of branching degree.

3.2. FT-IR Spectra. The spectra of the four DMSO-extracted hemicellulosic fractions, $\mathrm{H}_{30}, \mathrm{H}_{50}, \mathrm{H}_{70}$, and $\mathrm{H}_{90}$, which are precipitated by ethanol with concentration of $30 \%, 50 \%, 70 \%$, and $90 \%$, respectively, can be seen in Figure 2. The striking peaks around $3440 \mathrm{~cm}^{-1}$ are due to strong hydrogen-bonded $\mathrm{O}-\mathrm{H}$ stretching and two absorptions at 2922 and $2853 \mathrm{~cm}^{-1}$ are results of C-H stretching [29]. A sharp peak at $1741 \mathrm{~cm}^{-1}$ is attributed to the characteristic feature of $\mathrm{C}=\mathrm{O}$ stretching of carbonyl and acetyl groups in the hemicelluloses, which indicated that the acetyl ester bond could be preserved under the DMSO treatment [30]. Figure 2 clearly shows that the signals at $1741 \mathrm{~cm}^{-1}$ in spectra of $\mathrm{H}_{50}$ and $\mathrm{H}_{70}$ are stronger than those of $\mathrm{H}_{30}$ and $\mathrm{H}_{90}$; this is finely consistent with the 


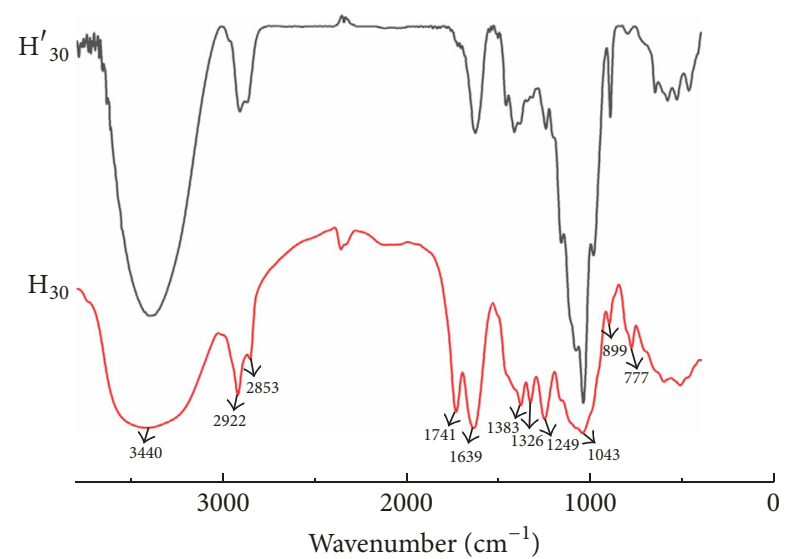

FIGURE 3: FT-IR spectra of DMSO-extracted fraction $\mathrm{H}_{30}$ and $\mathrm{NaOH}$-extracted fractions $\mathrm{H}_{30}^{\prime}$.

result of sugar analysis (Table 1). The signals at $1414 \mathrm{~cm}^{-1}$ are assigned to $\mathrm{CH}$ or $\mathrm{OH}$ bending [31]. Bands between 1166 and $1000 \mathrm{~cm}^{-1}$ are the typical evidences of xylan. A really weak signal around $1166 \mathrm{~cm}^{-1}$ is characteristic of the dominant $\mathrm{C}-\mathrm{O}$ stretching in $\mathrm{C}-\mathrm{O}-\mathrm{C}$ glycosidic linkages, and the contribution of $\mathrm{C}-\mathrm{OH}$ bending from arabinoxylan and the variation of the signal intensity reflect the degree of substitution by arabinose residues [30]. The absorption at $1043 \mathrm{~cm}^{-1}$ might be assigned to $\mathrm{C}-\mathrm{OH}$ bending [32], and the band at $897 \mathrm{~cm}^{-1}$, which corresponds to the $C_{1}$ group frequency or ring frequency, is characteristic of $\beta$-glycosidic linkages between the sugar units [33]. The signal at $777 \mathrm{~cm}^{-1}$ indicates that the arabinose, glucose, and glucuronic acid are probably linked by $\alpha$-glycosidic linkages [34]. The remaining bands at 1248 and $1383 \mathrm{~cm}^{-1}$ represent $\mathrm{O}-\mathrm{H}$ in-plane and C$\mathrm{H}$ bending vibrations, respectively [35]. The four spectra of $\mathrm{NaOH}$-extracted fractions are also similar, but they are different from that of DMSO-extracted fractions. For instance, the comparison of the two spectra $\mathrm{H}_{30}$ and $\mathrm{H}_{30}^{\prime}$ is exhibited in Figure 3. The sharp peak at $1741 \mathrm{~cm}^{-1}$ which is characteristic of $\mathrm{C}=\mathrm{O}$ stretching of carbonyl and acetyl groups can be only seen in spectrum of $\mathrm{H}_{30}$, while in $\mathrm{NaOH}$-extracted fractions, it was not found.

3.3. NMR Spectra. Many $\mathrm{NaOH}$-extracted hemicellulosic fractions have been characterized by NMR in our previous experiments; therefore, only structure elucidation of DMSOextracted hemicellulosic fractions is determined by means of $1 \mathrm{D}\left({ }^{1} \mathrm{H}\right.$ and $\left.{ }^{13} \mathrm{C}\right)$ and $2 \mathrm{D}$ (HSQC) NMR spectrometry now. Only spectrum of $\mathrm{H}_{50}$ is displayed here because the hemicellulosic fractions have similar structures based on the results of FT-IR spectra. Both the ${ }^{1} \mathrm{H}$ NMR and ${ }^{13} \mathrm{C}$ NMR spectra are compared with data in literatures and this allows the assignments of major peaks to be made. In Figure 4, signals of arabinofuranosyl and 4-O-methylglucuronic acid units appear in the 5.0-5.4 ppm region, while those from the xylopyranosyl residues are at $4.4-4.6 \mathrm{ppm}$ region. Signals at $4.26(\mathrm{H}-1), 2.98(\mathrm{H}-2), 3.18(\mathrm{H}-3), 3.44(\mathrm{H}-4), 3.02(\mathrm{H}-$ $\left.5_{\mathrm{ax}}\right)$, and $3.88\left(\mathrm{H}-5_{\mathrm{eq}}\right)$ ppm correspond to $1 \rightarrow 4$ linked $\beta$-Dxylose residues [36]. The peak that appeared at $5.30 \mathrm{ppm}$ is

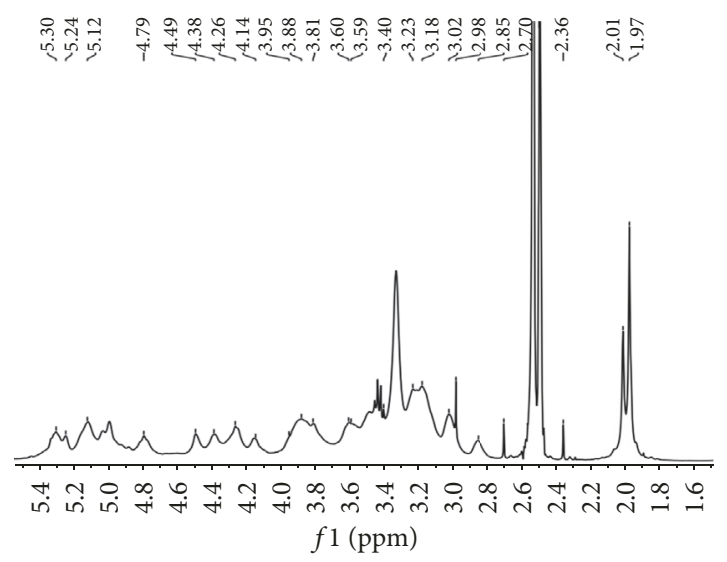

FIgURE $4:{ }^{1} \mathrm{H}$ NMR spectrum of hemicellulosic fraction $\mathrm{H}_{50}$.

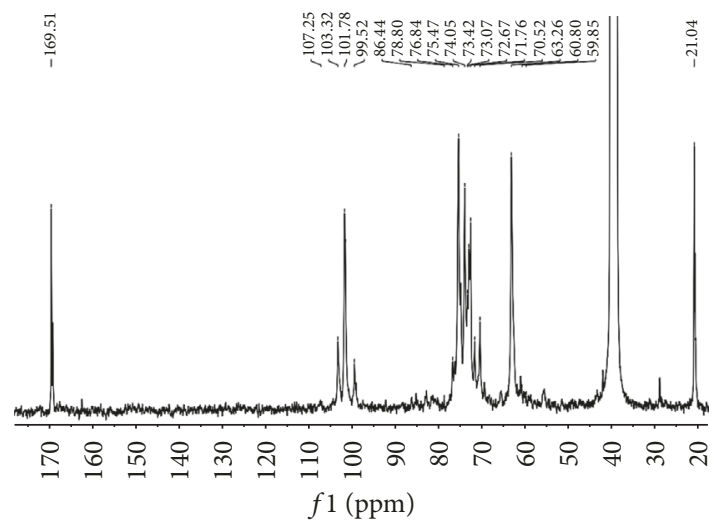

Figure 5: ${ }^{13} \mathrm{C}$ NMR spectrum of hemicellulosic fraction $\mathrm{H}_{50}$.

characteristic of terminal arabinofuranosyl residues linked to $\mathrm{O}-3$ in $\mathrm{H}_{50}$, and peaks at $3.81,3.59,3.95$, and 3.44 are attributed to $\mathrm{H}-2, \mathrm{H}-3, \mathrm{H}-4$, and $\mathrm{H}-5$ of arabinofuranosyl residues, respectively $[37,38]$. Other minor signals at 5.24 , $3.02,3.40$, and $3.23 \mathrm{ppm}$ are attributed to C-1, C-2, C-3, and the methoxyl group of 4-O-methyl-a-D-glucuronic acid residues, respectively $[37,39]$. The total balance of acetyl group was checked by integration of its $\mathrm{CH}_{3}$ - moieties at $2.05-2.30 \mathrm{ppm}$ [40]. The signal at $2.01 \mathrm{ppm}$ apparently indicates that the hemicellulosic fraction in $\mathrm{H}_{50}$ is highly acetylated, and the degree of acetyl substitution $\left(\mathrm{DS}_{\mathrm{AC}}\right)$ of the hemicellulosic fraction $\mathrm{H}_{50}$ was 0.23 (Table 1), which was determined by integration of the signals of acetyl groups at $2.01 \mathrm{ppm}$ and those of all carbohydrate signals. The peak at $5.12 \mathrm{ppm}$ indicates the 2-3-di- $O$-acetylated ( $\mathrm{H}-3$ integral at $\delta_{\mathrm{H}}$ 5.11-5.15) structure [37]. The $\mathrm{DS}_{\mathrm{AC}}$ of fractions $\mathrm{H}_{50}, \mathrm{H}_{70}$, and $\mathrm{H}_{90}$ are similar, while that of $\mathrm{H}_{30}$ is relatively lower, only about 0.13 .

The ${ }^{13} \mathrm{C}$ NMR spectrum (Figure 5) contains five major signals corresponding to those of $(1 \rightarrow 4)$ linked $\beta$-D-xylose residues. The signal at $101.78 \mathrm{ppm}$ is assigned to the anomeric region in a $\beta$-configuration of $\beta$-D-xylose. Signals at 72.67 , $73.42,75.47$, and $63.26 \mathrm{ppm}$ are characteristic for C-2, C$3, \mathrm{C}-4$, and $\mathrm{C}-5$ of $\beta$-D-xylose residues, respectively [41]. 
TABLE 3: ${ }^{1} \mathrm{H}$ and ${ }^{13} \mathrm{C}$ chemical shift (ppm) assignments for hemicellulosic fractions $\mathrm{H}_{50}$.

\begin{tabular}{|c|c|c|c|c|c|c|c|c|}
\hline \multirow{2}{*}{ Sugar residue } & \multicolumn{8}{|c|}{ Chem shift (ppm) H/C } \\
\hline & 1 & 2 & 3 & 4 & $5 \mathrm{ax}$ & 5 eq & 6 & $\mathrm{OMe}$ \\
\hline$\rightarrow 4)-\beta-\mathrm{Xylp}(1 \rightarrow$ & $101.78 / 4.26$ & $72.67 / 2.98$ & $73.42 / 3.18$ & $75.47 / 3.44$ & $63.26 / 3.02$ & $63.26 / 3.88$ & & \\
\hline$\alpha$-GlcAp- $(1 \rightarrow 2$ & $99.52 / 5.24$ & $70.52 / 3.02$ & $71.76 / 3.40$ & & & & & $58.82 / 3.23$ \\
\hline$\alpha$-Araf- $(1 \rightarrow 2,3$ & $107.25 / 5.30$ & $78.80 / 3.81$ & $76.84 / 3.59$ & $86.44 / 3.95$ & $61.12 / 3.44$ & & & \\
\hline$\rightarrow 4)-\beta$-Xylp $(1 \rightarrow, 2-\mathrm{O}-\mathrm{Ac}$ & & $73.07 / 4.38$ & & & & & & \\
\hline$\rightarrow 4)-\beta$-Xylp $(1 \rightarrow, 3-\mathrm{O}-\mathrm{Ac}$ & & & $74.05 / 4.79$ & & & & & \\
\hline
\end{tabular}

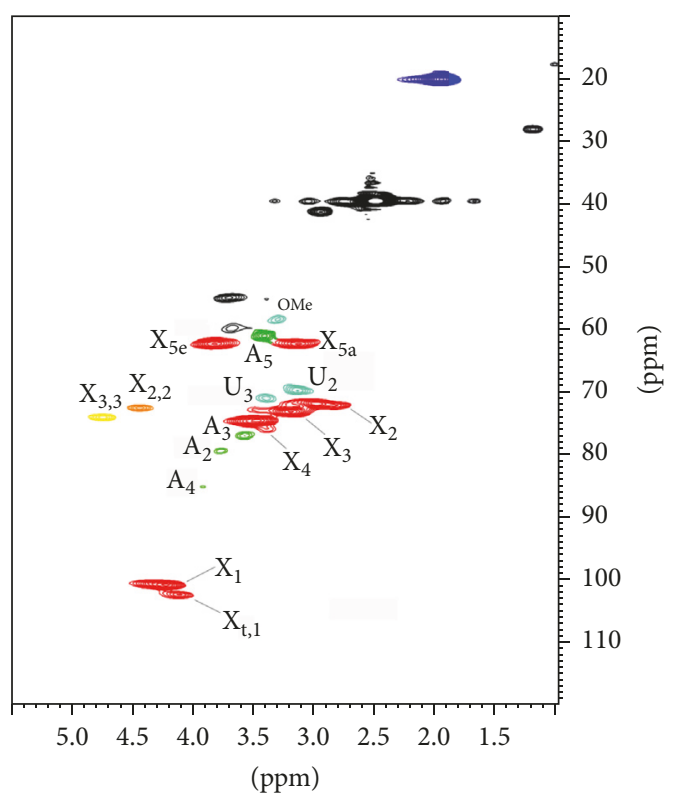

FIgURE 6: HSQC spectrum of hemicellulosic fraction $\mathrm{H}_{50}$. Designations are as follows: $\mathrm{X}, \mathrm{Xyl} p$; A, Araf; U, 4-O-Me- $\alpha-\mathrm{Glc} p \mathrm{~A} ; \mathrm{X}_{2}, 2-$ $O$-acetylated Xyl $p ; \mathrm{X}_{3}, 3-O$-acetylated Xyl $p$ Xt, nonacetylated xylose with terminal end.

A weak signal at $107.25 \mathrm{ppm}$ is assigned to C-1 of arabinofuranosyl residues. Peaks around 99.52, 70.52, 71.76, and $58.82 \mathrm{ppm}$ are original from $\mathrm{C}-1, \mathrm{C}-2, \mathrm{C}-3$, and $-\mathrm{OCH}_{3}$ in $4-$ $\mathrm{O}$-methylglucuronic acid residues [42]. Signals in the highfield resonance at $21.04 \mathrm{ppm}$ suggest the presence of $O$-acetyl groups in the hemicellulosic fraction, which is in accord with the results of FT-IR and ${ }^{1} \mathrm{H}$ NMR [43].

The chemical shift assignments of HSQC ${ }^{13} \mathrm{C} /{ }^{1} \mathrm{H}$ cross peaks for hemicellulosic fractions $\mathrm{H}_{50}$ are provided in detail by Table 3 . The dominating five signals in Figure 6 are at $101.78 / 4.26,72.67 / 2.98,73.42 / 3.18,75.47 / 3.44$, and $63.26 /(3.02,3.88) \mathrm{ppm}$, corresponding to $\mathrm{C}-1 / \mathrm{H}-1 \sim \mathrm{C}-5 / \mathrm{H}-5$ of 4 -linked $\beta$-xylose residues, respectively [44]. The cross peaks at 70.52/3.02, 71.76/3.40, and 58.82/3.23 ppm are unambiguously assigned to $\mathrm{C}-2 / \mathrm{H}-2, \mathrm{C}-3 / \mathrm{H}-3$, and $-\mathrm{OCH}_{3}$ of $4-\mathrm{O}-$ methylglucuronic acid residues substituted at $\mathrm{O}-2$ of xylose $[42,45]$. Two cross peaks at 73.07/4.38 and 74.05/4.79 ppm are due to the resonance of acetylation at positions 2 and 3 of 1,4 -linked $\beta$-Xyl $p$ residues, respectively [46]. Three relative weak signals that appear at 107.25/5.30, 78.80/3.81, and 76.84/3.59 are attributed to C-1/H-1, C-2/H-2, and C-3/H-3 of arabinofuranosyl residues [47]. The 2D integrals of $\mathrm{H}-2 / \mathrm{C}$ 2 and $\mathrm{H}-3 / \mathrm{C}-3$ cross peaks indicate that $\mathrm{O}$-acetyl groups at C-2 and C-3 are in proportion of $0.87 / 1.00$. The cross peak at $103.32 / 4.14$ is assigned to nonacetylated $\mathrm{Xyl}$ with terminal end [48]. On the basis of the NMR analysis, it can be inferred that the fraction $\mathrm{H}_{50}$ mainly consists of arabinose linked on position 3 of xylan, 4-O-methylglucuronic acid residues linked on position 2 of the xylan bone and acetyl groups linked on positions 2 and 3 . The other three hemicellulosic fractions have similar structures.

\section{Conclusions}

In this study, hemicelluloses from Neosinocalamus affinis were extracted by DMSO and $3 \% \mathrm{NaOH}$, sequentially precipitated by ethanol with gradient concentration. In gradient ethanol precipitation, results of sugar analysis suggest that Ara/Xyl and GlcA/Xyl of $\mathrm{NaOH}$-extracted fractions are ascending as the concentration of ethanol increases, while this trend was not found in DMSO-extracted fractions with different branch degree obtained by gradient ethanol precipitation. Through the characterization of GPC, FT-IR, and NMR, it can be inferred that DMSO is a kind of mild solvent which could preserve important structures of hemicelluloses such as acetyl groups. The DMSO-extracted Neosinocalamus affinis hemicelluloses mainly consist of highly acetylated arabino-4-O-methylglucurono- $(1 \rightarrow 4)-\beta$-D-xylan, in which acetyl residues are linked at positions $O-2$ and $O-3,4-O-$ Me- $\beta$-D-GlcA- $(1 \rightarrow 2)$ units are linked at position $O-2$, and arabinofuranosyl residues are linked at $\mathrm{O}-3$.

\section{Conflicts of Interest}

The authors declare that they have no conflicts of interest.

\section{Acknowledgments}

This work was supported by Fundamental Research Funds for the Central Universities (JC2015-03), National Natural Science Foundation of China (31470417), Ministries of Education (NCET-13-0670), Author of National Excellent Doctoral Dissertations of China (201458), and the National Program for Support of Top-Notch Young Professionals.

\section{References}

[1] J. M. O. Scurlock, D. C. Dayton, and B. Hames, "Bamboo: an overlooked biomass resource?” Biomass \& Bioenergy, vol. 19, no. 4, pp. 229-244, 2000. 
[2] L. S. Chan, W. H. Cheung, S. J. Allen, and G. McKay, "Separation of acid-dyes mixture by bamboo derived active carbon," Separation and Purification Technology, vol. 67, no. 2, pp. 166-172, 2009.

[3] E. L. Mui, W. Cheung, M. Valix, and G. McKay, "Activated carbons from bamboo scaffolding using acid activation," Separation and Purification Technology, vol. 74, no. 2, pp. 213-218, 2010.

[4] E. Yang, C. Yao, Y. Liu et al., "Bamboo-derived porous biochar for efficient adsorption removal of dibenzothiophene from model fuel," Fuel, vol. 211, pp. 121-129, 2018.

[5] P. Wu, Z. W. Wen, and G. Q. Gou, "Effect of main site factors on growth of Sinocalamusaffinis in mountain region of north Gui zhou," Journal of Mountain Agriculture and Biology, vol. 5, p. 4, 2007.

[6] J. Shaikh, D. D. Ankola, V. Beniwal, D. Singh, M. N. V. Ravi Kumar, and J. Pharm, "Nanoparticle encapsulation improves oral bioavailability of curcumin by at least 9 -fold when compared to curcumin administered with piperine as absorption enhancer," European Journal of Pharmaceutical Sciences, vol. 37, pp. 223-230, 2009.

[7] J. J. Rosnow, L. N. Anderson, R. N. Nair, E. S. Baker, and A. T. Wright, "Profiling microbial lignocellulose degradation and utilization by emergent omics technologies," Critical Reviews in Biotechnology, vol. 37, no. 5, pp. 626-640, 2017.

[8] L. Zhong, X. Peng, L. Song, D. Yang, X. Cao, and R. Sun, "Adsorption of $\mathrm{Cu} 2+$ and $\mathrm{Ni2}+$ from Aqueous Solution by Arabinoxylan Hydrogel: Equilibrium, Kinetic, Competitive Adsorption," Separation Science and Technology, vol. 48, no. 17, pp. 2659-2669, 2013.

[9] P. Peng and D. She, "Isolation, structural characterization, and potential applications of hemicelluloses from bamboo: A review," Carbohydrate Polymers, vol. 112, pp. 701-720, 2014.

[10] F. F. Silva, A. M. B. Alves, M. de Lurdes Serrano, and A. P. M. de Sousa, "Isolation and purification of concentrated and nonconcentrated hemicellulose alkaline extracts," Separation and Purification Technology, vol. 173, pp. 233-239, 2017.

[11] T. Y1lmaz and S. Tavman, "Modeling and Optimization of Ultrasound Assisted Extraction Parameters using Response Surface Methodology for Water Soluble Polysaccharide Extraction from Hazelnut Skin," Journal of Food Processing and Preservation, vol. 41, no. 2, Article ID e12835, 2017.

[12] M. J. Chung and S. Y. Wang, "Effects of peeling and steamheating treatment on basic properties of two types of bamboo culms (Phyllostachys makinoi and Phyllostachys pubescens)," Journal of Wood Science, vol. 63, no. 5, pp. 473-482, 2017.

[13] S. C. Singh and Z. V. P. Murthy, "Hemicelluloses separation from caustic-containing process stream by ultrafiltration," Separation Science and Technology, vol. 52, no. 14, pp. 2252-2261, 2017.

[14] X. Jiang, Q. Hou, W. Liu, H. Zhang, and Q. Qin, "Hemicelluloses removal in autohydrolysis pretreatment enhances the subsequent alkali impregnation effectiveness of poplar sapwood," Bioresource Technology, vol. 222, pp. 361-366, 2016.

[15] F. Peng, P. Peng, F. Xu, and R.-C. Sun, "Fractional purification and bioconversion of hemicelluloses," Biotechnology Advances, vol. 30, no. 4, pp. 879-903, 2012.

[16] G. R. Woolard, E. B. Rathbone, and L. Novellie, "DMSO-soluble hemicelluloses from the husk of Sorghum grain," Phytochemistry, vol. 16, no. 7, pp. 961-963, 1977.

[17] Z. Wang, T. Akiyama, T. Yokoyama, and Y. Matsumoto, "Fractionation and characterization of wood cell wall components of fagus crenata blume using licl/dmso solvent system," Journal of Wood Chemistry and Technology, vol.33, no. 3, pp. 188-196, 2013.
[18] S. Ray, J. Vigouroux, B. Quémener, E. Bonnin, and M. Lahaye, "Novel and diverse fine structures in LiCl-DMSO extracted apple hemicelluloses," Carbohydrate Polymers, vol. 108, no. 1, pp. 46-57, 2014.

[19] F. Peng, J.-L. Ren, F. Xu, J. Bian, P. Peng, and R.-C. Sun, "Fractional study of alkali-soluble hemicelluloses obtained by graded ethanol precipitation from sugar cane bagasse," Journal of Agricultural and Food Chemistry, vol. 58, no. 3, pp. 1768-1776, 2010.

[20] A. Sluiter, B. Hames, R. Ruiz et al., “Technical Report for Laboratory Analytical Procedure (LAP), NREL: Golden," Tech. Rep., CO, USA, 2010.

[21] D. Cheng, S. Jiang, and Q. Zhang, "Effect of hydrothermal treatment with different aqueous solutions on the mold resistance of moso bamboo with chemical and FTIR analysis," Bioresources, vol. 8, no. 1, pp. 371-382, 2013.

[22] V. M. Zelaya, P. V. Fernández, A. S. Vega, A. I. Mantese, A. A. Federico, and M. Ciancia, "Glucuronoarabinoxylans as major cell walls polymers from young shoots of the woody bamboo Phyllostachys aurea," Carbohydrate Polymers, vol. 167, pp. 240 249, 2017.

[23] C. D. Nandini and P. V. Salimath, "Carbohydrate composition of wheat, wheat bran, sorghum and bajra with good chapati/roti (Indian flat bread) making quality," Food Chemistry, vol. 73, no. 2, pp. 197-203, 2001.

[24] B. G. Smith and P. J. Harris, "The polysaccharide composition of Poales cell walls: Poaceae cell walls are not unique," Biochemical Systematics and Ecology, vol. 27, no. 1, pp. 33-53, 1999.

[25] F. Benaoun, C. Delattre, Z. Boual et al., "Structural characterization and rheological behavior of a heteroxylan extracted from Plantago notata Lagasca (Plantaginaceae) seeds," Carbohydrate Polymers, vol. 175, pp. 96-104, 2017.

[26] J. Freeman, J. L. Ward, O. Kosik et al., "Feruloylation and structure of arabinoxylan in wheat endosperm cell walls from RNAi lines with suppression of genes responsible for backbone synthesis and decoration," Plant Biotechnology Journal, vol. 15, no. 11, pp. 1429-1438, 2017.

[27] C. L. Wedig, E. H. Jaster, and K. J. Moore, "Hemicellulose Monosaccharide Composition and in Vitro Disappearance of Orchard Grass and Alfalfa Hay," Journal of Agricultural and Food Chemistry, vol. 35, no. 2, pp. 214-218, 1987.

[28] P. Peng, F. Peng, J. Bian, F. Xu, and R. Sun, "Studies on the starch and hemicelluloses fractionated by graded ethanol precipitation from bamboo phyllostachys bambusoides f. shouzhu Yi," Journal of Agricultural and Food Chemistry, vol. 59, no. 6, pp. 26802688, 2011.

[29] W.-Q. Kong, C.-D. Gao, S.-F. Hu, J.-L. Ren, L.-H. Zhao, and R.C. Sun, "Xylan-modified-based hydrogels with temperature/pH dual sensitivity and controllable drug delivery behavior," Materials, vol. 10, no. 3, article no. 304, 2017.

[30] L. Wang, H.-M. Liu, and G.-Y. Qin, "Structure characterization and antioxidant activity of polysaccharides from Chinese quince seed meal," Food Chemistry, vol. 234, pp. 314-322, 2017.

[31] P. Peng, M. Zhai, D. She, and Y. Gao, "Synthesis and characterization of carboxymethyl xylan-g-poly(propylene oxide) and its application in films," Carbohydrate Polymers, vol. 133, Article ID 10111, pp. 117-125, 2015.

[32] S. Philippe, P. Robert, C. Barron, L. Saulnier, and F. Guillon, "Deposition of cell wall polysaccharides in wheat endosperm during grain development: Fourier transform-infrared microspectroscopy study," Journal of Agricultural and Food Chemistry, vol. 54, no. 6, pp. 2303-2308, 2006. 
[33] A. Palaniappan, S. S. Yuvaraj, S. Sonaimuthu, and U. Antony, "Characterization of xylan from rice bran and finger millet seed coat for functional food applications," Journal of Cereal Science, vol. 75, pp. 296-305, 2017.

[34] A. P. Chandrasekaran, S. Sivamani, and V. Ranjithkumar, "Characterization of combined organic-inorganic acid-pretreated cassava stem," International Journal of Environmental Science and Technology, vol. 14, no. 6, pp. 1291-1296, 2017.

[35] J. Lehto, J. Louhelainen, M. Huttunen, and R. Alén, "Spectroscopic analysis of hot-water- and dilute-acid-extracted hardwood and softwood chips," Spectrochimica Acta Part A: Molecular and Biomolecular Spectroscopy, vol. 184, pp. 184-190, 2017.

[36] Z. Hromádková, Z. Košt'álová, N. Vrchotová, and A. Ebringerová, "Non-cellulosic polysaccharides from the leaves of small balsam (Impatiens parviflora DC.)," Carbohydrate Research, vol. 389, no. 1, pp. 147-153, 2014.

[37] D. Morais de Carvalho, A. M. Abad, D. V. Evtuguin et al., "Isolation and characterization of acetylated glucuronoarabinoxylan from sugarcane bagasse and straw," Carbohydrate Polymers, vol. 156, pp. 223-234, 2017.

[38] S. N. Sun, T. Q. Yuan, M. F. Li, X. F. Cao, F. Xu, and Q. Y. Liu, "Structural characterization of hemicelluloses from bamboo culms (neosinocalamusaffinis)," Cellulose Chemistry and Technology, vol. 46, no. 3-4, pp. 165-176, 2012.

[39] F. Peng, J. Bian, P. Peng et al., "Separation and characterization of acetyl and non-acetyl hemicelluloses of Arundo donax by ammonium sulfate precipitation," Journal of Agricultural and Food Chemistry, vol. 60, no. 16, pp. 4039-4047, 2012.

[40] D. V. Evtuguin, J. L. Tomás, A. M. S. Silva, and C. P. Neto, "Characterization of an acetylated heteroxylan from Eucalyptus globulus Labill," Carbohydrate Research, vol. 338, no. 7, pp. 597604, 2003.

[41] Z. Jiang, H. Zhang, T. He et al., "Understanding the cleavage of inter- and intramolecular linkages in corncob residue for utilization of lignin to produce monophenols," Green Chemistry, vol. 18, no. 14, pp. 4109-4115, 2016.

[42] M. R. Vignon and C. Gey, "Isolation, $1 \mathrm{H}$ and 13C NMR studies of (4-O-methyl-D-glucurono)-D- xylans from luffa fruit fibres, jute bast fibres and mucilage of quince tree seeds," Carbohydrate Research, vol. 307, no. 1-2, pp. 107-111, 1998.

[43] T. Heinze, T. Liebert, and A. Koschella, Esterification of polysaccharides, Springer Science Business Media, 2006.

[44] F. Peng, J.-L. Ren, F. Xu, J. Bian, P. Peng, and R.-C. Sun, "Fractionation of alkali-solubilized hemicelluloses from delignified populus gansuensis: Structure and properties," Journal of Agricultural and Food Chemistry, vol. 58, no. 9, pp. 5743-5750, 2010.

[45] E. Dinand and M. R. Vignon, "Isolation and NMR characterisation of a (4-O-methyl-D-glucurono)-D-xylan from sugar beet pulp," Carbohydrate Research, vol. 330, no. 2, pp. 285-288, 2001.

[46] S. Saghir, M. S. Iqbal, A. Koschella, and T. Heinze, "Ethylation of arabinoxylan from Ispaghula (Plantago ovata) seed husk," Carbohydrate Polymers, vol. 77, no. 1, pp. 125-130, 2009.

[47] X. Zhang, M. Chen, H. Wang, C. Liu, A. Zhang, and R. Sun, "Characterization of Xylan- graft -Polycaprolactone Copolymers Prepared in Ionic Liquid," Industrial \& Engineering Chemistry Research, vol. 54, no. 24, pp. 6282-6290, 2015.

[48] A. Teleman, J. Lundqvist, F. Tjerneld, H. Stålbrand, and O. Dahlman, "Characterization of acetylated 4-O-methylglucuronoxylan isolated from aspen employing ${ }^{1} \mathrm{H}$ and ${ }^{13} \mathrm{C}$ NMR spectroscopy," Carbohydrate Research, vol. 329, no. 4, pp. 807815,2000 . 


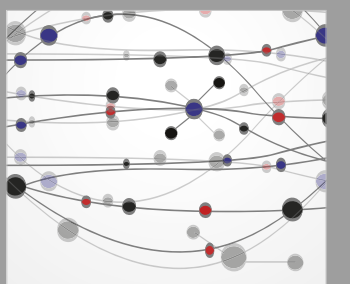

The Scientific World Journal
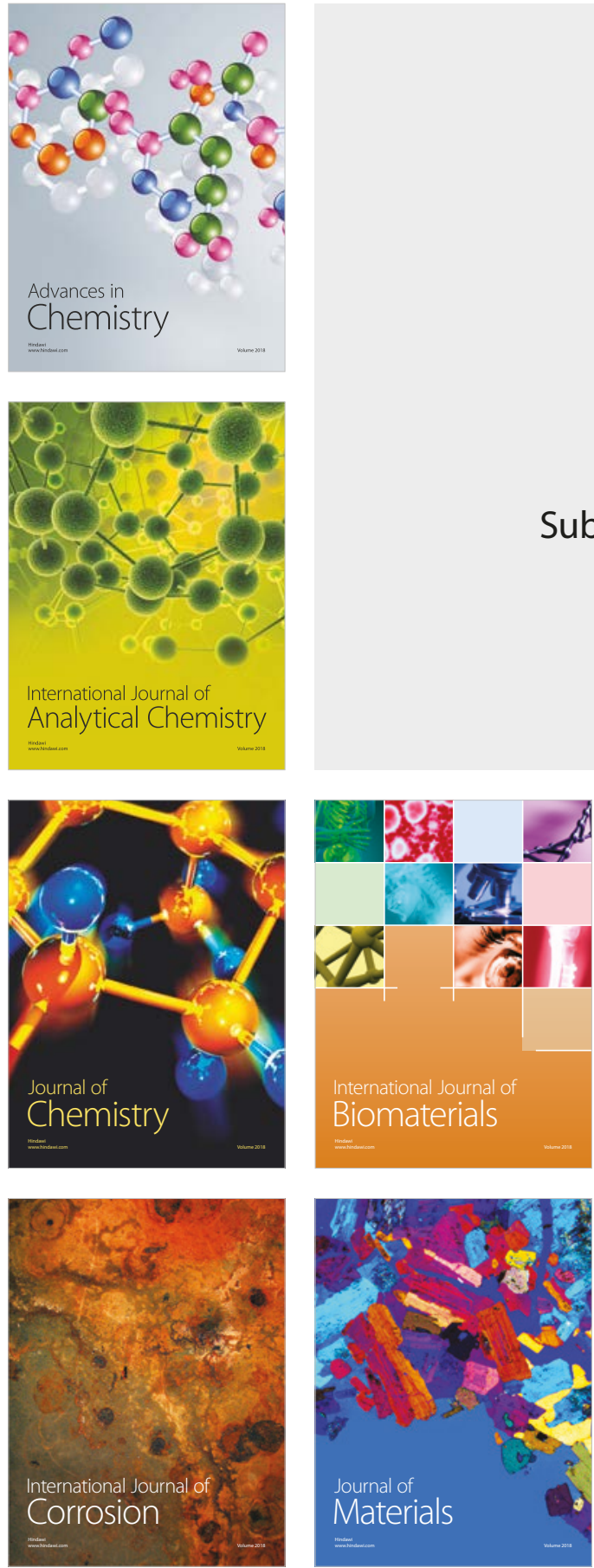

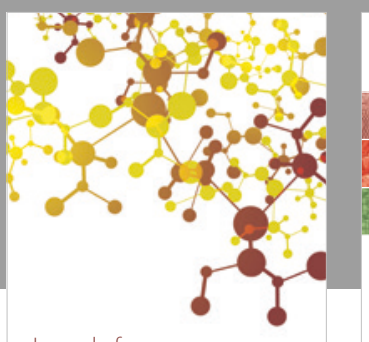

Journal of

Applied Chemistry
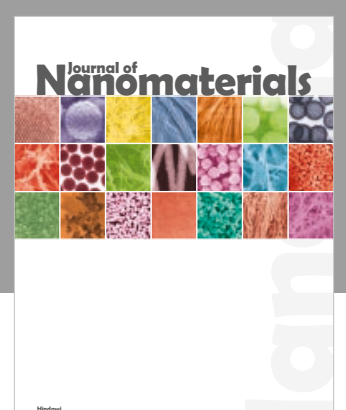

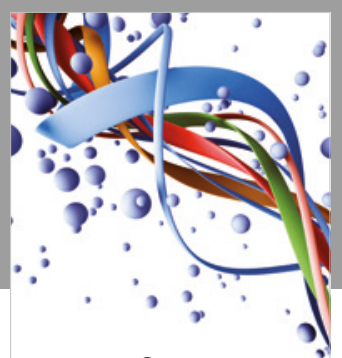

Scientifica

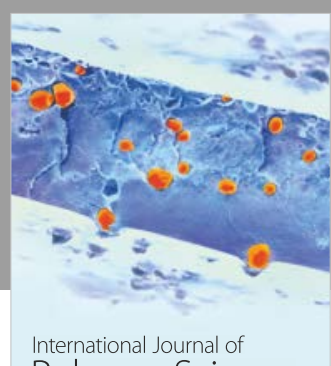

Polymer Science

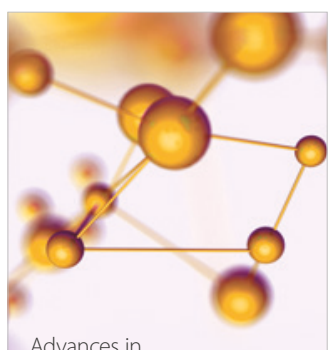

Physical Chemistry
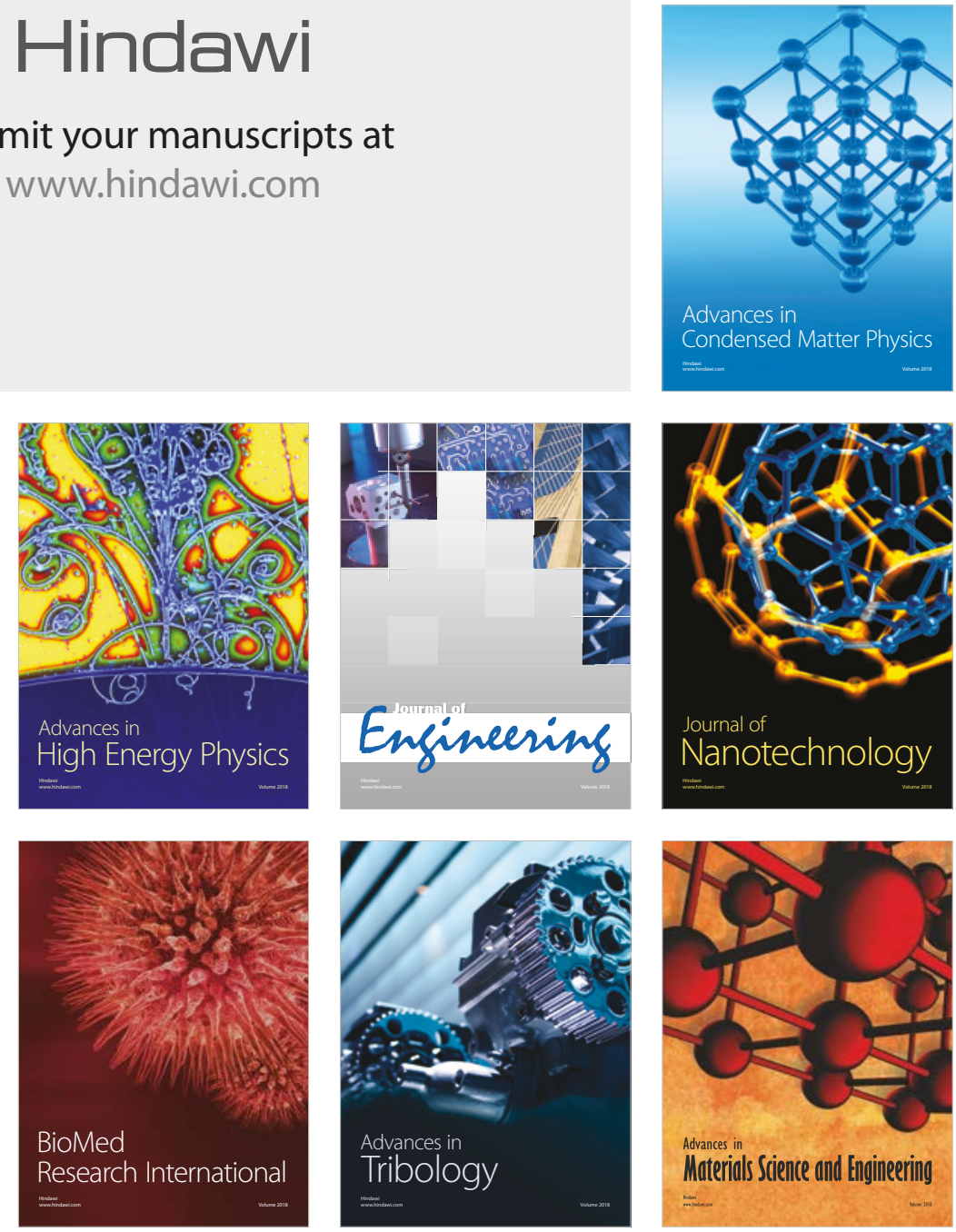